\title{
Use of hormonal contraceptives to control menstrual bleeding: attitudes and practice of Brazilian gynecologists
}

This article was published in the following Dove Press journal:

International Journal of Women's Health

26 November 2013

Number of times this article has been viewed

\author{
María Y Makuch' \\ Maria José D Osis' \\ Karla Simonia de Pádua ${ }^{1,2}$ \\ Luis Bahamondes ${ }^{3}$ \\ 'Center for Research in Reproductive \\ Health (CEMICAMP), ${ }^{2}$ Prof Dr José \\ Aristodemo Pinotti Women's Hospital, \\ University of Campinas, ${ }^{3}$ Department \\ of Obstetrics and Gynaecology, \\ School of Medical Sciences, University \\ of Campinas, and National Institute \\ of Hormones and Women's Health, \\ Campinas, São Paulo, Brazil
}

Background: The purpose of this study was to assess the attitudes and prescribing practices of Brazilian obstetricians and gynecologists regarding use of contraceptive methods to interfere with menstruation and/or induce amenorrhea.

Methods: We undertook a nationwide survey of Brazilian obstetricians and gynecologists selected using a computer-generated randomization system. Participants completed a questionnaire on prescription of contraceptives and extended/continuous regimens of combined oral contraceptives (COCs).

Results: In total, $79.2 \%$ of Brazilian obstetricians and gynecologists reported that $20 \%-40 \%$ of their patients consulted them for menstrual-related complaints and $26 \%-34 \%$ of the gynecologists reported that $21 \%-40 \%$ of their patients consulted them for reduction in the intensity, frequency, and/or duration of menstrual bleeding. Overall, $93 \%$ stated that medically induced amenorrhea represents no risk to women's health and $82.5 \%$ said that they prescribed contraceptives to control menstruation or induce amenorrhea. The contraceptives most commonly prescribed were extended-cycle 24/4 or 26/2 COC regimens and the levonorgestrel-releasing intrauterine system. Poisson regression analysis showed that Brazilian obstetricians and gynecologists prescribing contraceptives to control menstruation or induce amenorrhea consider extended-use or continuous-use COC regimens to be effective for both indications (prevalence ratio 1.23 [95\% confidence interval 1.09-1.40] and prevalence ratio 1.28 [95\% confidence interval 1.13-1.46], respectively). They also prescribed COCs with an interval of $24 / 4$ or $26 / 2$ to control bleeding patterns (prevalence ratio 1.10 [95\% confidence interval 1.01-1.21]).

Conclusion: Brazilian obstetricians and gynecologists were favorably disposed toward prescribing extended-use or continuous-use COC regimens for control of menstrual bleeding or to induce amenorrhea on patient demand.

Keywords: menstruation, induced amenorrhea, gynecologists, Brazil, hormonal contraceptives

\section{Introduction}

More women are seeking counseling and medical options to reduce the intensity, duration, and/or frequency of menstruation or to become amenorrheic. ${ }^{1-6}$ Over recent decades, menstruation has been able to be avoided with the use of hormonal contraceptives. ${ }^{1-3}$ At present, the safest and commonest strategy for menstrual control consists of extended-use or continuous-use combined oral contraceptive (COC) regimens rather than the conventional $21 / 7$ pill regimen ${ }^{3-5,7}$ or extended use of the vaginal ring or contraceptive patch, albeit the experience with these methods for menstrual control is still limited. ${ }^{8}$
Correspondence: María Y Makuch Center for Research in Reproductive Health (CEMICAMP), Caixa Postal 618I, Campinas I3084-97I, São Paulo, Brazil

Tel +55 I9 32892856

$\mathrm{Fax}+551932892440$

Email mmakuch@cemicamp.org.br 
A study conducted in several countries in 1987 reported that women's desire to control menstruation varied according to their age, education level, occupation, and degree of menstrual discomfort. ${ }^{9}$ However, more recent studies have presented evidence of the growing tendency of women to accept use of contraceptive methods that may provoke amenorrhea, longer intervals between menstrual periods, or less bleeding flow. ${ }^{10-14}$ Another study reported no significant difference between adolescents and adult women regarding attitudes toward menstrual bleeding. ${ }^{11}$

Studies conducted between 1999 and 2006 in the Netherlands, Germany, France, and Italy showed that $25 \%, \sim 41 \%, 57 \%$, and $29 \%$, respectively, of interviewed women reported that they wished to become amenorrheic. ${ }^{5,12-14}$ One US study reported that $69 \%$ of women wanted amenorrhea or to reduce the frequency of bleeding episodes, ${ }^{3}$ and another showed that $60 \%$ of women who embarked on extended-use COCs to induce amenorrhea continued using them for up to 2 years. ${ }^{15}$ In two Brazilian surveys, approximately $60 \%$ of women reported disliking menstruation, approximately $65 \%$ reported that they would prefer not to bleed at all, a similar proportion reported that they would use COCs to control menstrual bleeding, and more than $80 \%$ reported that they would use COCs to induce amenorrhea. Further, the women reported that they would like more information on medically induced amenorrhea. ${ }^{16,17}$

The increasing number of women requesting information and treatment to control their bleeding pattern highlights the need for an indepth understanding of the attitudes of obstetricians and gynecologists (OBGYN) regarding this practice and their prescribing habits. Patient-physician communication is an important skill in medical practice and an essential component of the patient-physician relationship..$^{18-20}$ The quality of patient-physician communication depends to a great extent on the physician's attitudes and ability to understand and discuss the patient's concerns and to provide information.

US-based studies ${ }^{15,21}$ of OBGYN and family planning health care professionals reported that $70 \%-92 \%$ of physicians who prescribed COCs prescribed them in extendedcycle regimens and $\mathrm{OBGYN}$ were more prone to this practice. Also, in Germany and Austria, OBGYN were favorably disposed to use of extended-COCs for control of bleeding. ${ }^{5,22}$

There is still a paucity of data in developing countries on the attitudes and practices of OBGYN regarding use of hormonal contraceptive methods and control of menstrual bleeding. The objective of this study was to assess attitudes and prescribing practices on the part of OBGYN regarding hormonal contraceptive methods that may modify menstrual patterns and eventually lead to medically induced amenorrhea.

\section{Materials and methods Design}

A nationwide descriptive study was conducted using a nonprobability sample of Brazilian OBGYN. The research protocol was approved by the institutional review board at the University of Campinas. A letter of invitation was prepared in which we explained the objectives of the study, the voluntary nature of participation, and that those OBGYN who answered and returned the questionnaires were consenting to participate in the study. The procedure used to obtain consent was approved by the institutional review board.

Computer-generated randomization was used to select the OBGYN from a list of OBGYN registered with the pharmaceutical company that partially supported this study. This list included 17,978 OBGYN registered in the country. Sales representatives from the pharmaceutical company delivered the questionnaires to the OBGYN invited to complete the questionnaire and later collected them. On their routine visits, the sales representatives gave a package of research material consisting of the letter explaining the study, the questionnaire, and an envelope in which the questionnaire was to be returned. If the envelope was open at the time of collection, the sales representative sealed it in the presence of the OBGYN. No incentive was offered to participants for completion of the questionnaire.

\section{Data collection}

A self-completed questionnaire was developed and pretested. The questionnaire included questions on sociodemographic characteristics, the percentage of patients consulting for menstrual disorders according to the perception of the OBGYN, the concerns and questions regarding monthly bleeding raised by women during consultations, the attitude of the OBGYN toward hormonal contraceptives for the purpose of controlling bleeding, and his/her prescribing habits regarding these products, monthly menstrual bleeding, and medically induced amenorrhea. For those who reported prescribing hormonal contraceptives including $\mathrm{COCs}$, questions were then asked about extended-use COC regimens, defined here as regimens in which the hormonecontaining pill is taken for more than 28 days followed by a scheduled hormone-free interval, or continuous-use COCs, defined here as uninterrupted use of hormone-containing pills. OBGYN who reported prescribing COCs were then 
asked to answer questions regarding the characteristics of the women for whom this kind of prescription is indicated and to what extent their patients expressed a desire to change their menstrual pattern. Questions were also included on the clinical benefits and risks of COCs, extended-use and continuous-use COC regimens, and use of other hormonal contraceptive methods to control bleeding.

\section{Data analysis}

The sociodemographic characteristics of the participants were compared using the $\chi^{2}$ test and the Student's $t$-test. Associations between physician age, number of years since graduation, place of work (large/small cities), and knowledge were evaluated using the $\chi^{2}$ test. The Mann-Whitney $U$ test and Student's $t$-test were used to evaluate the association between attitudes and prescribing habits. A Poisson multiple regression model with the backward selection method was used to assess whether there were any correlations between age, sex, year in which the physician completed their medical residency in Obstetrics and Gynecology, the size of the city in which the physician lived, whether he/she was working in the private or public sector, their opinion that menstrual control or medically induced amenorrhea is detrimental to health, and their knowledge regarding contraceptive methods that are effective in controlling bleeding or inducing amenorrhea. Statistical significance was established at $P<0.005$. The data were analyzed using Statistical Package for the Social Sciences version 13.0 software (SPSS, Chicago, IL, USA).

\section{Results}

Of the 8,989 questionnaires distributed, 2,137 (23.8\%) were returned completed. The mean \pm standard deviation age was $48.8 \pm 11.1$ (range 22-84) years and the respondents had completed their OBGYN residency in 1990.9 \pm 10.2 (range 1952-2012). Almost half (48.4\%) of the respondents were women, $58.6 \%$ practiced medicine in a city with more than 500,000 inhabitants, and $61.2 \%$ worked in both the private and public sectors (Table 1). Of the OBGYN who worked in the public sector, $39.7 \%$ reported working in a hospital, $38.0 \%$ in a primary health care facility, and $16.2 \%$ in a teaching hospital.

According to $79 \%$ of the OBGYN, $20 \%-40 \%$ of their patients consulted them for complaints related to menstrual bleeding, and they estimated that $21 \%-40 \%$ of their patients had a medical indication for reducing the frequency $(26 \%)$, intensity (34\%), or number of days of menstruation (30\%). Further, almost $30 \%$ of the OBGYN estimated that $21 \%-40 \%$
Table I Percentage distribution of OBGYN according to where they worked $(n=2,153)$

\begin{tabular}{lll}
\hline Characteristics & $\mathbf{n}$ & $\%$ \\
\hline Population of city in which respondents & practiced medicine* & \\
$<50,000$ inhabitants & 82 & 4.0 \\
$50,00 \mathrm{I}-100,000$ inhabitants & 172 & 8.4 \\
I00,00I-500,000 inhabitants & 596 & 29.1 \\
$>500,000$ inhabitants & $1,20 \mathrm{I}$ & 58.6 \\
Working in & & \\
Private sector & 732 & 34.8 \\
Public sector & 89 & 4.2 \\
Both & 1,296 & 61.2 \\
\hline
\end{tabular}

Notes: *Data missing for 102 physicians; "data missing for 36 physicians.

Abbreviation: OBGYN, obstetricians and gynecologists.

of their patients would like to reduce the frequency, intensity, or number of days of menstruation, respectively (Table 2).

Of the responding OBGYN, 67.2\% reported that a continuous regimen of hormonal contraceptives to control menstrual bleeding on demand represented a risk only for those women with contraindications according to the World Health Organization guidelines, ${ }^{23}$ and a further 30\% reported that it posed no risk whatsoever to women. According to $93 \%$ of the participating OBGYN, amenorrhea or delayed menstruation induced by contraceptives represented no risk at all to women's health (Table 3). Further, 66.9\% reported that they prescribed hormonal contraceptives to delay menstruation and $82.5 \%$ prescribed them to reduce the frequency of menstrual periods. Younger and female OBGYN were more likely to prescribe these COC regimens $(P<0.001)$. Regarding the prescription of hormonal contraceptives to induce amenorrhea, $81 \%$ reported that they prescribed them either at the women's request or when medically indicated. OBGYN who prescribed contraceptives to control bleeding stated that there were no restrictions on this practice according to age or parity $(P<0.001)$. The contraceptives most commonly prescribed to control menstruation were extended-use COC regimens (79.4\%), the levonorgestrelreleasing intrauterine system (72.7\%), and $24 / 4$ or $26 / 2$ COC regimens $(P<0.0001$, Table 4$)$.

OBGYN reported that the women who requested contraceptives to control bleeding frequency were afraid that hormones could affect their body $(84.0 \%)$ or cause future infertility $(80.2 \%)$, considered that amenorrhea is not natural $(75.0 \%)$, and were worried about their health $(75.0 \%$, Table 5). Most of the OBGYN (99.0\%) reported that they used hormonal contraceptives to control their own menstrual bleeding or prescribed them for their partners. The main reasons given for this practice were that hormonal contraceptives reduce symptoms of the premenstrual syndrome (89.7\%), 
Table 2 Proportion of women consulting for menstrual complaints or because they wished to change their menstrual pattern, according to OBGYN $(n=2,153)$

\begin{tabular}{lll}
\hline OBGYN responses & $\mathbf{n}$ & $\%$ \\
\hline $\begin{array}{l}\text { Percentage of women with a medical indication for reducing frequency } \\
\text { of menstrual bleeding* }\end{array}$ & \\
$\leq 20 \%$ & 1,083 & 51.6 \\
$21 \%-40 \%$ & 548 & 26.1 \\
$41 \%-60 \%$ & 205 & 9.8 \\
$>60 \%$ & 95 & 4.5 \\
None & 58 & 2.8 \\
Do not know & 109 & 5.2 \\
Percentage of women wishing to reduce frequency of menstrual & \\
periods** & & \\
$\leq 20 \%$ & 892 & 42.5 \\
$21 \%-40 \%$ & 612 & 29.1 \\
$41 \%-60 \%$ & 302 & 14.4 \\
$>60 \%$ & 162 & 7.7 \\
None & 50 & 2.4 \\
Do not know & 82 & 3.9
\end{tabular}

Percentage of women with a medical indication for reducing intensity of menstrual bleeding***

$\begin{array}{lll}\leq 20 \% & 788 & 37.3 \\ 21 \%-40 \% & 718 & 34.0 \\ 41 \%-60 \% & 395 & 18.7 \\ >60 \% & 167 & 7.9 \\ \text { None } & 7 & 0.3 \\ \text { Do not know } & 35 & 1.7\end{array}$

Percentage of women wishing to reduce intensity of menstrual bleeding ${ }^{\pi}$ $\begin{array}{lll}\leq 20 \% & 694 & 32.8\end{array}$ $21 \%-40 \% \quad 645 \quad 30.5$

$41 \%-60 \% \quad 429 \quad 20.3$

$\begin{array}{lll}>60 \% & 289 & 13.7\end{array}$

$\begin{array}{lll}\text { None } & 16 & 0.8\end{array}$

Do not know $43 \quad 2.0$

Percentage of women with a medical indication for reducing number of days of menstruation ${ }^{\text {TाT }}$

$\begin{array}{lll}\leq 20 \% & 894 & 42.5 \\ 21 \%-40 \% & 642 & 30.5 \\ 41 \%-60 \% & 328 & 15.6 \\ >60 \% & 129 & 6.1 \\ \text { None } & 28 & 1.3 \\ \text { Do not know } & 82 & 3.9\end{array}$

Percentage of women wishing to reduce the number of days of menstruation $^{+}$

\begin{tabular}{lll}
$\leq 20 \%$ & 715 & 34.0 \\
$21 \%-40 \%$ & 637 & 30.2 \\
$41 \%-60 \%$ & 394 & 18.7 \\
$>60 \%$ & 263 & 12.5 \\
None & 27 & 1.3 \\
Do not know & 70 & 3.3 \\
\hline
\end{tabular}

Notes: *Data missing for 55 physicians; ${ }^{* *}$ data missing for 53 physicians; ****data missing for 43 physicians; "data missing for 37 physicians; "Tाata missing for 50 physicians; +data missing for 47 physicians.

Abbreviation: OBGYN, obstetricians and gynecologists.

diminish the intensity of menstrual bleeding (86.6\%), and are not detrimental to health (37.8\%).

The Poisson multiple regression model showed that the OBGYN who reported prescribing hormonal contraceptives to reduce the frequency of bleeding or to induce amenorrhea
Table 3 Opinion of OBGYN regarding whether continuous use of hormonal contraceptives to control menstruation represents a risk to women $(n=2,153)$

\begin{tabular}{|c|c|c|}
\hline & $\mathbf{n}$ & $\%$ \\
\hline \multicolumn{3}{|c|}{ Is continuous use of hormonal contraceptives on demand for the } \\
\hline \multicolumn{3}{|c|}{ purpose of controlling menstrual bleeding a risk to women's health?* } \\
\hline Yes, for women with contraindications & 1,416 & 67.2 \\
\hline No, not for any women & 645 & 30.6 \\
\hline Yes, for all women & 32 & 1.5 \\
\hline Do not know & 13 & 0.6 \\
\hline \multicolumn{3}{|c|}{$\begin{array}{l}\text { Is amenorrhea or delayed menstruation induced by hormonal } \\
\text { contraceptives a risk to women's health?** }\end{array}$} \\
\hline No, not for any women & 1,914 & 93.0 \\
\hline Yes, for all women & 82 & 4.0 \\
\hline Do not know & 63 & 3.1 \\
\hline
\end{tabular}

Notes: *Data missing for 47 physicians; $* *$ data missing for 94 physicians. Abbreviation: OBGYN, obstetricians and gynecologists.

consider extended-use and continuous-use COCs to be effective for both indications (prevalence ratio [PR] 1.23, 95\% confidence interval [CI] $1.09-1.40$ and PR $1.28,95 \%$ CI 1.13-1.46, respectively) and also consider the levonorgestrelreleasing intrauterine system to be effective for both purposes (PR 1.14, 95\% CI 1.01-1.27 and PR 1.17, 95\% CI 1.05-1.31, respectively). They also reported that when they recommend use of hormonal contraceptives to control bleeding patterns, they prescribe a COC regimen with a short pill-free interval (24/4 or $26 / 2$, PR $1.10,95 \%$ CI 1.01-1.21, Table 6).

Table 4 Prescribing habits of OBGYN regarding bleeding control and methods they prescribe

\begin{tabular}{|c|c|c|}
\hline & $\mathbf{n}$ & $\%$ \\
\hline Prescribes methods for delaying menstruation* & 1,399 & 66.9 \\
\hline $\begin{array}{l}\text { Prescribes methods for women to bleed less } \\
\text { frequently** }\end{array}$ & $\mathrm{I}, 727$ & 82.5 \\
\hline Prescribes methods to induce amenorrhea** & 1,805 & 86.2 \\
\hline \multicolumn{3}{|c|}{ In which situation does the physician prescribe these methods? } \\
\hline At the woman's request & 188 & 9.1 \\
\hline When OBGYN suggest use & 185 & 9.0 \\
\hline Both cases & 1,672 & 81.0 \\
\hline Does not prescribe these methods & 19 & 0.9 \\
\hline
\end{tabular}

Hormonal contraceptives that OBGYN reported they prescribed for reducing intensity, frequency, and number of days of menstruation or for inducing amenorrhea

\begin{tabular}{lll} 
Extended COC regimens & $\mathrm{I}, 644$ & 79.4 \\
LNG-IUS & $\mathrm{I}, 506$ & 72.7 \\
$24 / 4$ or 26/2 COC regimens & $\mathrm{I}, 163$ & 56.2 \\
Progestin-only pill & 994 & 48.0 \\
Etonogestrel-releasing implant & 378 & 18.3 \\
2I/7 COC regimen & 377 & 18.2 \\
Injectable & 238 & 11.5 \\
\hline
\end{tabular}

Notes: *Data missing for 61 physicians; $* *$ data missing for 59 physicians; "data missing for 89 physicians.

Abbreviations: OBGYN, obstetricians and gynecologists; $\mathrm{COC}$, combined oral contraceptive; LNG-IUS, levonorgestrel-releasing intrauterine system. 
Table 5 Questions raised by women when requesting hormonal contraceptives to control menstrual bleeding according to experience of participating OBGYN

\begin{tabular}{lll}
\hline Questions ${ }^{\#, *}$ & $\mathbf{n}$ & $\%$ \\
\hline Afraid that hormones will affect their body & $\mathrm{I}, 732$ & 84.0 \\
Afraid that they will become infertile due to continuous & $\mathrm{I}, 655$ & 80.2 \\
hormone use & & \\
Concerned that it is not natural & $\mathrm{I}, 547$ & 75.0 \\
Concerned with health in general & $\mathrm{I}, 547$ & 75.0 \\
They want to know where the menstruation goes & $\mathrm{I}, 260$ & 61.1 \\
Concerned that it may affect their sexual relationship & 490 & 23.8 \\
Other queries & 98 & 4.8 \\
\hline
\end{tabular}

Notes: "more than one answer allowed; *data missing for 90 physicians.

Abbreviation: OBGYN, obstetricians and gynecologists.

\section{Discussion}

The results presented here on the perspectives and practice of Brazilian OBGYN regarding monthly menstruation and use of hormonal contraceptives with the aim of interfering with menstrual patterns and/or to induce amenorrhea are, to the best of our knowledge, the first in Latin America. Nearly a quarter of the distributed questionnaires were

Table 6 Variables associated with several practices reported by OBGYN (Poisson regression multiple analysis)

\begin{tabular}{|c|c|c|c|}
\hline Practice/variable & PR & $95 \% \mathrm{Cl}$ & $P$-value \\
\hline \multicolumn{4}{|c|}{$\begin{array}{l}\text { Prescribes hormonal contraceptives for women to bleed less often } \\
(n=2,030)\end{array}$} \\
\hline $\begin{array}{l}\text { Considers that continuous COCs } \\
\text { are effective }\end{array}$ & 1.23 & $1.09-1.40$ & $<0.002$ \\
\hline $\begin{array}{l}\text { Considers that the LNG-IUS is } \\
\text { effective }\end{array}$ & + & 7 & 27 \\
\hline \multicolumn{4}{|c|}{$\begin{array}{l}\text { Prescribes hormonal contraceptives to women to induce amenorrhea } \\
(n=2,030)\end{array}$} \\
\hline $\begin{array}{l}\text { Considers that continuous COCs } \\
\text { are effective }\end{array}$ & 1.28 & $1.13-1.46$ & $<0.001$ \\
\hline $\begin{array}{l}\text { Considers that the LNG-IUS is } \\
\text { effective }\end{array}$ & 1.17 & 1.05 & 0.005 \\
\hline \multicolumn{4}{|c|}{$\begin{array}{l}\text { Prescribes hormonal contraceptives to women for the purpose of } \\
\text { changing her bleeding pattern, as proposed by the woman herself } \\
(n=2,056)\end{array}$} \\
\hline $\begin{array}{l}\text { Considers that a COC regimen } \\
\text { with a short pill-free interval } \\
(24 / 4 \text { or } 26 / 2) \text { is effective }\end{array}$ & 1.10 & $1.01-1.21$ & 0.040 \\
\hline
\end{tabular}

Notes: Variables in the model: age (years); sex; year in which the physician completed residency in obstetrics and gynecology (up to 1992 and after 1992); number of inhabitants in the city in which the physician lives $(\leq 100,000$ inhabitants and $>100,000$ inhabitants); works in the private sector (Yes/No); works in the public sector (Yes/No); believes that menstrual control or amenorrhea induced by contraceptive use is detrimental to health $(\mathrm{Yes} / \mathrm{No}$ ); considers that $\mathrm{COCs}$ with short pill-free interval are effective for control of bleeding ( $\mathrm{Yes} / \mathrm{No}$ ); considers that $\mathrm{COCs}$ with a 21/7 regimen are effective for control of bleeding (Yes/No); considers that continuous-use COCs are effective for control of bleeding (Yes/No); considers that injectable contraceptives are effective for control of bleeding $(\mathrm{Yes} / \mathrm{No})$; considers that the LNG-IUS is effective for control of bleeding (Yes/No); considers that the etonogestrel-releasing implant is effective for control of bleeding (Yes/No).

Abbreviations: OBGYN, obstetricians and gynecologists; PR, prevalence ratio; $\mathrm{Cl}$, confidence interval; COC, combined oral contraceptive; LNG-IUS, levonorgestrel-releasing intrauterine system. returned completed. This return rate was higher than for a similar German study which reported a response rate of only $18 \%$ for 9,000 questionnaires distributed. ${ }^{5}$ Additionally, a USbased study which distributed a smaller number of questionnaires reported a $32.7 \%$ response rate, ${ }^{24}$ and another study done in the US that did not report the number of questionnaires distributed obtained a response from 460 OBGYN..$^{25}$

Given that it is important for women to have access to different hormonal contraceptive options and that these methods may be used not only for contraception but also for bleeding control, it is relevant to broaden our knowledge on the perspectives of OBGYN. The contraceptive method chosen by a woman and its effect on her menstrual pattern has to be meaningful in the context of her life. OBGYN are some of the key health care professionals who give information, clarify doubts, listen to and understand concerns, and establish a dialogue with the woman.

Our findings show that, according to the perspectives of the OBGYN interviewed, menstrual bleeding is an important issue in clinical practice. Overall, the OBGYN showed favorable attitudes regarding use of contraceptives for control of menstrual bleeding or to induce amenorrhea, and no differences were found according to their sociodemographic characteristics. Our results regarding the decision to prescribe hormonal contraceptives are in contrast with those of a US study showing that physicians who practice in urban locations are more likely to report prescribing extended-use COC regimens. ${ }^{24}$

Most of the OBGYN interviewed were favorably disposed to prescribing extended-use or continuous-use COC regimens, the levonorgestrel-releasing intrauterine system, and 24/4 and 26/2 COC regimens to control bleeding or to induce amenorrhea, either when medically indicated or at the woman's request, with the only exception being those women for whom hormonal contraceptives are contraindicated according to World Health Organization eligibility criteria. ${ }^{23}$ This positive response rate is in agreement with the $92 \%$ rate reported from a US study, ${ }^{26}$ and could be accounted for by the fact that dedicated products for extended-use COCs are approved and available on the US market. ${ }^{3,25,26}$ However, there are no dedicated products for this purpose in Brazil, although we can speculate that the positive response rate may be a consequence of ongoing medical education in obstetrics and gynecology.

Menstrual bleeding control and medically induced amenorrhea requires two-way communication between women and physicians. It has been reported that the practices of physicians are influenced by their attitudes; ${ }^{4}$ however, it may 
be argued that they are also affected by patient attitudes. In our study, OBGYN reported that many patients were concerned about whether hormones could affect their health and wanted to be certain about the safety of interfering with menstrual bleeding. The perceptions of the OBGYN interviewed regarding women's concerns about use of hormonal contraceptives for control of menstrual bleeding were similar to the concerns reported by Brazilian women in two recent nationwide studies. ${ }^{16,17}$

We can also speculate that these questions may affect the decision of health care professionals to prescribe hormonal contraceptives. On the one hand, women need to understand that use of a contraceptive method that can induce amenorrhea is not harmful to their health. On the other, OBGYN need to discuss amenorrhea openly with their patients, taking women's perceptions and concerns into account, explain that this practice will not damage their health, and provide adequate information on the different contraceptive options available. There is evidence that the quality of patient-physician communication is important in ensuring both patient compliance with treatment and patient satisfaction. ${ }^{18,19,24,27,28}$

The fact that almost all the physicians interviewed reported that they used hormonal contraceptives to control their own menstrual bleeding or prescribed them for their partners may be a good indication that they are indeed open to prescribing these contraceptives for this purpose. It has been reported elsewhere that physicians' personal contraceptive use affects their prescribing and counseling practices. ${ }^{29}$

When the OBGYN in our study were questioned about the hormonal methods most commonly indicated for control of bleeding or to induce amenorrhea, many also mentioned the levonorgestrel-releasing intrauterine system. One of the benefits of this system is a reduction in the intensity, frequency, and days of menstrual bleeding, as well as its ability to induce amenorrhea. However, this effect is not expected to occur within a short period of time following insertion. ${ }^{30-32}$

The main strengths of this study were the large number of Brazilian OBGYN interviewed, the wide age range of participants, their distribution throughout the different regions of the country, and the fact that they practiced in both the public and private sectors. The main limitations were that only about one quarter of the OBGYN approached answered the questionnaire and that the information about the number and percentages of the women attended due to menstrual complaints was self-reported by the responders, with no review of medical records. These findings related to the attitudes and prescribing habits of Brazilian OBGYN may contribute toward gaining a greater understanding and improving patient-physician interaction regarding the use of hormonal contraceptives and control of menstrual bleeding in other settings.

\section{Conclusion}

Brazilian OBGYN were favorably disposed toward prescribing hormonal contraceptives, including extended-use and continuous-use COC regimens, to control menstrual bleeding and/or to induce amenorrhea both for medical reasons and on demand.

\section{Acknowledgment}

This study was partially funded by the Brazilian National Research Council (grant 573747/2008-3) and by Bayer, Brazil. The sponsors were not involved in the design of the study, in any part of the data entry or data analysis procedures, or in preparing or reviewing the manuscript.

\section{Author contributions}

All authors were involved in the design and development of the study and in preparation of the manuscript.

\section{Disclosure}

The authors report no conflicts of interest in this work.

\section{References}

1. Snow R, Hardy E, Kneuper E, Hebling EM, Hall G. Women's responses to menses and nonbleeding intervals in the USA, Brazil and Germany. Contraception. 2007;76:23-29.

2. Ferrero S, Abbamonte LH, Giordano M, et al. What is the desired menstrual frequency of women without menstruation-related symptoms? Contraception. 2006;73:537-541.

3. Edelman A, Lew R, Cwiak C, Nichols M, Jensen J. Acceptability of contraceptive-induced amenorrhea in a racially diverse group of US women. Contraception. 2007;75:450-453.

4. Glasier AF, Smith KB, van der Spuy ZM, et al. Amenorrhea associated with contraception - an international study on acceptability. Contraception. 2003;67:1-8.

5. Wiegratz I, Hommel HH, Zimmermann T, Kuhl H. Attitude of German women and gynecologists towards long-cycle treatment with oral contraceptives. Contraception. 2004;69:37-42.

6. Rutter W, Knight C, Vizzard J, Mira M, Abraham S. Women's attitude to withdrawal bleeding and their knowledge and beliefs about the oral contraceptive pills. Med J Austr. 1988;149:417-419.

7. Davis MG, Reape KZ, Hait H. A look at the long-term safety of an extended-regimen OC. J Fam Pract. 2010;59:E3.

8. Barreiros FA, Guazzelli CA, Barbosa R, de Assis F, de Araújo FF. Extended regimens of the contraceptive vaginal ring: evaluation of clinical aspects. Contraception. 2010;81:223-225.

9. World Health Organization. A cross-cultural study of menstruation: implications for contraceptive development and use. Stud Fam Plann. 1981;12:3-16.

10. Loudon NB, Foxwell M, Potts DM, Guild AL, Short RV. Acceptability of an oral contraceptive that reduces the frequency of menstruation: the tri-cycle pill regimen. BMJ. 1977;2:487-490. 
11. Aubeny E. Are monthly menstrual periods optional? A European perspective. Reprod Health Matters. 2007;15:183-185.

12. Tonkelaar I, Oddens BJ. Preferred frequency and characteristics of menstrual bleeding in relation to reproductive status, oral contraception use, and hormone replacement therapy use. Contraception. 1999;59: 357-362.

13. Reproduction Humaine et Hormones, Symtomes liés au cycle: doivent-ils rester une fatalité? Résultat d'une grande enquête miroir TNS Sofres. Médecins/patientes sur l'attitude vis à vis des règles et la prise en charge des symptômes liés aux cycles [Human Reproduction and Hormones, Symptoms-cycle: should they remain a fatality? Result of a large mirror survey TNS Sofres. Doctors / patients on the attitude towards rules and management of symptoms associated with menstrual cycles]. SOFRES Survey. 2006, Vol XIX, n Spécial, p. 1-11. Available from: http://www.tns-sofres.com/resultats-de-recherche-rapide?filtreS ecteur $=32 \&$ filtreBesoin=none\#. Accessed October 31, 2013. French.

14. Ferrero S, Abbamonte LH, Giordano M, et al. What is the desired menstrual frequency of women without menstruation-related symptoms? Contraception. 2006;73:537-541.

15. Sulak PJ, Carl J, Gopalakrishnan I, Coffee A, Kuehl TJ. Outcomes of extended oral contraceptive regimens with a shortened hormone-free interval to manage breakthrough bleeding. Contraception. 2004;70: 281-287.

16. Makuch MY, Duarte-Osis MJ, de Pádua KS, Petta C, Bahamondes L. Opinion and experience of Brazilian women regarding menstrual bleeding and use of combined oral contraceptives. Int J Gynaecol Obstet. 2012;117:5-9.

17. Makuch MY, Osis MJ, Petta CA, de Pádua KS, Bahamondes L. Menstrual bleeding: perspective of Brazilian women. Contraception. 2011;84:622-627.

18. Ong LMI, de Haes JCJM, Hoos AM, Lammes FB. Doctor-patient communication: a review of the literature. Soc Sci Med. 1995;40: 903-918.

19. Participants in the Bayer-Fetzer Conference on physician-patient communication in medical education. Essential elements of communication in medical encounters: the Kalamazoo consensus statement. Acad Med. 2001;76:390-393.

20. Lipkin M. Physician-patient interaction in reproductive counseling. Obstet Gynecol. 1996;88(Suppl 3):31S-40S.
21. Sulak PJ, Buckley T, Kuehl TJ. Attitudes and prescribing preferences of health care professionals in the United States regarding use of extendedcycle oral contraceptives. Contraception. 2006;73:41-45.

22. Wiegratz I, Galiläer K, Sänger N, Rody A, Kuhl H, Schleussner E. Prescribing preferences and personal experience of female gynaecologists in Germany and Austria regarding use of extended-cycle oral contraceptives. Eur J Contracept Reprod Health Care. 2010;15: 405-412.

23. World Health Organization. Medical eligibility criteria for contraceptive use. Available from: http://www.who.int/reproductivehealth/publications/ family_planning/9789241563888/en/. Accessed October 13, 2013.

24. Frederick CE, Edelman A, Carlson NE, Rosenberg KD, Jensen JT. Extended-use oral contraceptives and medically induced amenorrhea: attitudes, knowledge and prescribing habits of physicians. Contraception. 2011;84:384-389.

25. Seval DL, Buckley T, Kuehl TJ, Sulak PJ. Attitudes and prescribing patterns of extended-cycle oral contraceptives. Contraception. 2011;84:71-75.

26. Coffee AL, Sulak PJ, Kuehl TJ. Long-term assessment of symptomatology and satisfaction of an extended oral contraceptive regimen. Contraception. 2007;75:444-449.

27. Moore PJ, Adler NE, Robertson PA. Medical malpractice: the effect of doctor-patient relations on medical patient perceptions and malpractice intentions. West J Med. 2000;173:244-250.

28. Hall JA, Roter DL, Katz NR. Meta-analysis of correlates of provider behavior in medical encounters. Med Care. 1988;26:657-675.

29. Frank E, Elon L. Clinical and personal relationships between oral contraceptive and hormone replacement therapy use among US women physicians. Menopause. 2003;10:133-141.

30. Monteiro I, Bahamondes L, Diaz J, Perrotti M, Petta C. Therapeutic use of levonorgestrel-releasing intrauterine system in women with menorrhagia: a pilot study. Contraception. 2002;65:325-328.

31. Hidalgo M, Bahamondes L, Perrotti M, DiazJ, Dantas-Monteiro C, Petta C. Bleeding patterns and clinical performance of the levonorgestrelreleasing intrauterine system (Mirena) up to two years. Contraception. 2002;65:129-132.

32. Kaunitz AM, Bissonnette F, Monteiro I, Lukkari-Lax E, Muysers C, Jensen JT. Levonorgestrel-releasing intrauterine system or medroxyprogesterone for heavy menstrual bleeding: a randomized controlled trial. Obstet Gynecol. 2010;116:625-632.
International Journal of Women's Health

\section{Publish your work in this journal}

The International Journal of Women's Health is an international, peerreviewed open-access journal publishing original research, reports, editorials, reviews and commentaries on all aspects of women's healthcare including gynecology, obstetrics, and breast cancer. The manuscript management system is completely online and includes

\section{Dovepress}

a very quick and fair peer-review system, which is all easy to use. Visit http://www.dovepress.com/testimonials.php to read real quotes from published authors. 